\title{
Reflets
}

Revue ontaroise d'intervention sociale et communautaire

\section{RESO, le regroupement des parents et amis des enfants sourds et malentendants franco-ontariens}

Volume 4, numéro 2, automne 1998

Personnes vivant avec une incapacité

URI : https://id.erudit.org/iderudit/026237ar

DOI : https://doi.org/10.7202/026237ar

Aller au sommaire du numéro

Éditeur(s)

Reflets : Revue ontaroise d'intervention sociale et communautaire

ISSN

1203-4576 (imprimé)

1712-8498 (numérique)

Découvrir la revue

Citer ce document

(1998). RESO, le regroupement des parents et amis des enfants sourds et

malentendants franco-ontariens. Reflets, 4(2), 209-211.

https://doi.org/10.7202/026237ar

Tous droits réservés $(\subset$ Reflets : Revue ontaroise d'intervention sociale et communautaire, 1998
Ce document est protégé par la loi sur le droit d'auteur. L'utilisation des services d'Érudit (y compris la reproduction) est assujettie à sa politique d'utilisation que vous pouvez consulter en ligne.

https://apropos.erudit.org/fr/usagers/politique-dutilisation/ 


\section{RESO, le regroupement des parents et amis des enfants sourds et malentendants franco-ontariens ${ }^{1}$}

\section{Ce que nous sommes}

RESO est formé d'un groupe de parents, de grands-parents et d'amis touchés par la surdité d'un proche. Nous savons par expérience que la surdité, quand elle entre dans une famille, vient «déranger» nos vies.

Nous sommes des parents qui avons des questions, beaucoup de questions. Parfois, nous nous sentons inquiets devant les décisions à prendre et souvent, très souvent, isolés.

Nous avons mis sur pied ce réseau de parents et d'amis pour créer des liens, pour nous rencontrer et partager des préoccupations, des idées, des informations, des expériences.

\section{Ce que nous croyons}

Tout enfant - sourd, entendant ou malentendant - est une personne qui a le potentiel de grandir et de se développer. La surdité ne doit pas couper l'enfant de sa famille et de son milieu qui sont à la base de son développement.

Tout enfant sourd ou malentendant a le droit d'accéder à une langue qu'il comprend aisément, que ce soit la langue des signes, le français écrit et s'il en est capable, le français parlé. 
Toute famille a le droit d'apprendre à communiquer avec l'enfant sourd ou malentendant.

Tout enfant sourd ou malentendant a le droit à un enseignement dans un milieu et dans une langue qui lui permettent de comprendre spontanément.

Tout enfant sourd a le droit à des amis qui communiquent facilement avec lui.

\section{Services de RESO}

RESO offre aux parents et amis des rencontres avec d'autres parents, d'autres amis, d'autres enfants sourds, des adultes sourds, des enseignants, des intervenants, des interprètes, des personnes ressources.

Les rencontres et les activités mettent l'emphase sur les échanges avec d'autres personnes qui vivent chaque jour avec la surdité, ses défis et ses richesses.

Les contacts entre les membres brisent l'isolement et permettent de trouver des éléments de réponse aux questions. En devenant membre, vous devenez une ressource pour les autres.

RESO met sur pied des projets qui sensibilisent la population et les institutions francophones de l'Ontario aux besoins des parents, des amis et des enfants sourds et malentendants.

\section{Réalisations de RESO depuis 1995}

- Incorporation comme groupe à but non-lucratif en Ontario et recrutement d'une centaine de membres à travers l'Ontario français.

- Rassemblement annuel d'une fin de semaine (participation: 80-100 personnes) avec kiosques d'information et ateliers à la mesure des besoins des membres. 
- Activités sociales pour toute la famille:Noël, St-Valentin, Partie de sucre en avril, etc.

- École d'été d'une semaine pour les parents et les enfants avec des spécialistes et des personnes ressources.

- Partenariat avec le Centre Jules Léger et son programme de surdité.

- Demande de création d'un service de pré-maternelle pour les tout-petits avec leurs frères et sœurs au Centre Jules Léger.

- Cours de langue des signes du Québec (LSQ) pour les parents et les amis.

- Publication d'une lettre "Allô! RESO», envoyée aux membres à tous les deux mois.

- Partenariat avec le Centre Jules Léger et l'Université d'Ottawa pour la formation d'enseignants pour les enfants sourds.

\section{Nos projets}

- Produire des outils pédagogiques pour appuyer l'apprentissage de la LSQ pour les parents et amis des enfants sourds.

- Faire reconnaître officiellement la LSQ en travaillant pour que les cours I, II, III, IV, offerts à l'Université d'Ottawa deviennent des cours crédités.

- Faire mieux connaître RESO et offrir ou développer des services si nécessaires pour les familles touchées par la surdité.

- Développer des partenariats avec les collèges communautaires, la télévision française de l'Ontario, les télévisions communautaires, etc., pour que des cours de LSQ soient accessibles à toutes les personnes intéressées de l'Ontario français.

1. Pour plus de renseignements, vous pouvez joindre : Francine Drouin, présidente, au téléphone (613) 488-2618,ATS : (613) 488-3195, télécopieur: (613) 488-2730 ou Diane Vachon, secrétaire générale au téléphone :(613) 487-2722, télécopieur: (613) 487-4195 ou courriel : L'adresse est la suivante : RESO, C.P. 175, Clarence Creek, Ontario, K0A 1N0 